\title{
Fenologia e demanda térmica das videiras 'Isabel' e 'Rubea' sobre diferentes porta-enxertos na Região Norte do Paraná
}

\section{Phenology and thermal demand of 'Isabel' and 'Rubea' grapevines on different rootstocks in North of Paraná}

\author{
Alessandro Jefferson Sato ${ }^{1 *}$; Bruno Jubileu da Silva ${ }^{2}$; Cristiano Ezequiel dos \\ Santos $^{2}$; Roseneide Bertolucci ${ }^{3}$; Roberta dos Santos 3 ; Mariana Carielo ${ }^{3}$; Marília \\ Cherobin Guiraud $^{3}$; Inês Cristina de Batista Fonseca ${ }^{4}$; Sérgio Ruffo Roberto ${ }^{4}$
}

\section{Resumo}

\begin{abstract}
Este trabalho teve como objetivo caracterizar o comportamento fenológico, bem como determinar a demanda térmica das videiras 'Isabel' (Vitis labrusca) e 'Rubea' (V. labrusca $\mathrm{x}$ (V. labrusca $\times$ V. vinifera) x V. labrusca) enxertadas sobre os porta-enxertos IAC 766 Campinas, IAC 572 Jales e 420-A, destinadas à elaboração de suco de uva no Norte do Paraná. O experimento foi conduzido em um pomar experimental pertencente ao Centro Tecnológico da Cooperativa Corol, localizado no município de Rolândia, PR. O plantio dos porta-enxertos foi realizado em julho de 2002, e a enxertia das copas em julho de 2003. O delineamento experimental adotado foi o inteiramente casualizado, com 4 repetições, com os tratamentos arranjados no esquema fatorial $2 \times 3$ ( 2 cultivares copa e 3 cultivares porta-enxerto). As plantas foram conduzidas no sistema GDC (Geneva Double Curtain) no espaçamento de 2,0 m entre plantas e 3,5 m entre linhas. Para o estudo da duração dos estádios fenológicos da videira, foram etiquetados quatro esporões por parcela, onde, a partir da poda de frutificação, foi determinado o tempo decorrido, em dias, até a gema-algodão, a brotação, o aparecimento da inflorescência, o florescimento, o início da maturação e a colheita. A demanda térmica foi calculada empregando o somatório de graus-dia (GD), desde a poda até a colheita ,e entre cada um dos subperíodos. Pelos resultados obtidos, determinou-se que a duração do ciclo para a videira 'Isabel', sobre os porta-enxertos IAC 766 Campinas, IAC 572 Jales e 420-A, foi de 148,142 e 167 dias, respectivamente e a demanda térmica durante todo o ciclo para estas combinações de $1.260,9,1.260,9$ e 1.541,6 GD, respectivamente. Para a videira 'Rubea', sobre os mesmos porta-enxertos a duração do ciclo foi de 134, 134 e 132 dias, respectivamente. A demanda térmica para o período entre a poda e a colheita foi de $1.003,8 ; 1.003,8$ e $999,5 \mathrm{GD}$, respectivamente.
\end{abstract}

Palavras-chave: Uva, graus-dia, suco de uva, Vitis labrusca

\begin{abstract}
The aim of this research was to characterize the phenological behavior, as well as to determine the thermal demand of 'Isabel' (Vitis labrusca) and 'Rubea' (V. labrusca $\times$ (V. labrusca $\times$ V. vinifera) $\mathrm{x}$. labrusca) grapevines for grape juices in the North of Paraná. The trial was carried out in a experimental vineyard located at Technology Center of Corol Cooperative, located at Rolândia, PR. The vineyard was

\footnotetext{
1 Aluno regular do curso de pós-graduação em Agronomia da Universidade Estadual de Londrina. Centro de Ciências Agrárias. Londrina, PR Fone: 43 33417108. Email: ajsato82@yahoo.com.br

2 Aluno regular do curso de pós-graduação em Agronomia da Universidade Estadual de Londrina.

3 Acadêmico do curso de graduação em Agronomia da Universidade Estadual de Londrina .

4 Prof. Adjunto do curso de Agronomia da Universidade Estadual de Londrina.

* Autor para correspondência
} 
established in July, 2002 and grafted in 2003. The design was used as the statistical model with four replications in a factorial $2 \times 3$ project ( 2 grapevines and 3 rootstocks). The plants were cultivated in GDC (Geneva Double Curtain) system, in $2.0 \times 3.5 \mathrm{~m}$ spacing. To evaluate the duration of each phenological stage (in days) four spurs were marked per plot, where was evaluated in days until the bud swell, to beginning of shot growth, to visible cluser, to flowering; to early ripening and to harvest. The thermal demand was calculated using the degree-days sum from pruning to harvest, as well for each subperiod. The results show that the duration of the pruning to harvest for grape 'Isabel' grafted on rootstocks IAC 766 Campinas, IAC 572 Jales and 420-A was 148, 142 and 167 days, respectively and the thermal demand to this combination was $1,260.9 ; 1,260.9$ and $1,541.6 \mathrm{GD}$, respectively. For 'Rubea' grafted on rootstocks IAC 766 Campinas, IAC 572 Jales and 420-A the cycle was 134, 134 and 132 days, respectively and the thermal demand from pruning to harvest for even combinations was $1,003.8 ; 1,003.8$ and $999.5 \mathrm{GD}$, respectively.

Key words: Grape, degree-days, grape juice, Vitis labrusca

\section{Introdução}

A indústria brasileira de sucos de uvas surgiu a partir da década de 70, com a produção de suco de uva concentrado no Rio Grande do Sul (CAMARGO, 2005). Em 2005 foram produzidos cerca de 105 milhões de litros de suco de uva (MELLO, 2006), sendo que a produção brasileira ocorre, em sua maioria, no Estado do Rio Grande do Sul, que é responsável por $95 \%$ da produção total, o que permite considerar este Estado como referência nacional na elaboração deste produto (MELLO, 2005).

A produção de sucos de uvas no Brasil é uma atividade em amplo crescimento, sendo que a comercialização, em 2005, foi aproximadamente 25 \% maior do que em 2004, com um total de 131 milhões de litros, entre sucos de uva concentrado e integral. O consumo per capita brasileiro ainda é baixo, quando comparado a países europeus, porém cresceu muito nos últimos anos. Em 1995, o consumo era de $0,15 \mathrm{~L}$ e em 2005 este consumo atingiu a média de 0,53 L per capita (MELLO, 2006).

No Paraná, um dos principais Estados produtores de uva, a viticultura consolidou-se na produção de uvas finas, para consumo in natura (CORRÊA; BOLIANI, 2000), com duas safras anuais, obtendo uma colheita entre os meses de dezembro e janeiro e outra entre maio e junho (ROBERTO et al., 2002). Porém, devido à intensa produção de uvas de mesa no Estado em determinadas safras, tem sido observado uma baixa rentabilidade da cultura, devido ao grande volume de uvas produzido no país, o que sobrecarrega o mercado e leva à queda no valor do produto.
Desta forma, alguns setores, como cooperativas agroindustriais, têm procurado diversificar a produção de uvas no Paraná. A produção de uvas para a elaboração de sucos se mostra uma alternativa para os produtores, pois é possível diversificar a produção sem muitas alterações nos sistemas de cultivo.

O suco produzido em muitos países de tradição vitícola é elaborado com uvas Vitis vinifera, tanto de cultivares brancas como de tintas. Porém, o suco brasileiro é elaborado principalmente com uvas do grupo das americanas e híbridas (RIZZON; MANFROI; MENEGUZZO, 1998), mais adaptado ao Sul do Brasil, com produções abundantes e de elevada qualidade para a elaboração de sucos e outros derivados (CAMARGO, 2003).

A uva 'Isabel' (Vitis labrusca) é a base para o suco brasileiro, pois se trata de uma cultivar muito bem adaptada às condições climáticas do Sul do Brasil, altamente fértil, com produções abundantes (EMPRESA BRASILEIRA DE PESQUISA AGROPECUÁRIA, 2006), e representa atualmente cerca de $45 \%$ da produção de uvas no Estado do Rio Grande do Sul. Entretanto, o suco elaborado desta cultivar apresenta deficiência em cor, devido à falta de pigmentos.

Além da 'Isabel', são utilizadas neste processo outras cultivares americanas, geralmente para agregar cor ao suco, como, por exemplo, a 'Rubea' (CAMARGO, 2005). Esta cultivar foi lançada pela Embrapa Uva e Vinho em 1999, para a elaboração de sucos. Destaca-se pela coloração e por possuir sabor e aroma típicos de cultivares americanas 
(EMPRESA BRASILEIRA DE PESQUISA AGROPECUÁRIA, 2005).

Entre os porta-enxertos mais importantes na viticultura do Norte do Paraná, estão o 'IAC 766 Campinas' e o 'IAC 572 Jales'. Ambos imprimem maior vigor às cultivares copa, utilizados na produção de uvas de mesa em regiões tropicais e subtropicais brasileiras (NACHTIGAL; CAMARGO, 2004). O porta-enxerto '420-A' é também utilizado nesta região, porém induz às copas a um menor vigor, sendo interessante para locais onde se deseja uma produção mais limitada, pois permite melhor controle do crescimento das brotações (CAMARGO, 2003).

Entretanto, na implantação de determinada cultivar em uma região onde o cultivo é pouco conhecido, é necessário estudos do comportamento fenológico, em função das condições edafo-climaticas locais. Para Mullins, Bouquet e Williams (1992), conhecer o comportamento fenológico é de grande importância, pois possibilita ao viticultor prever o desenvolvimento da cultura e as épocas em que será necessária maior demanda de mão-de-obra e tratos culturais.

Outro fator importante na escolha de uma cultivar é conhecer demanda térmica que as plantas necessitam para completarem os estádios fenológicos, permitindo ao viticultor prever, por exemplo, a provável data de colheita, de acordo com os dados climáticos de cada região (SENTELHAS, 1998). Essa quantidade de energia é denominada soma térmica, e geralmente é expressa em grausdia (PEDRO JÚNIOR; SENTELHAS, 2003).

O objetivo deste trabalho, foi portanto, determinar o tempo decorrido da poda até diferentes estádios fenológicos, e a demanda térmica das uvas 'Isabel' e 'Rubea' enxertadas sobre os porta enxertos IAC 766 Campinas, IAC 572 Jales e 420-A, destinadas à elaboração de suco na Região Norte do Estado do Paraná.

\section{Material e Métodos}

$\mathrm{O}$ experimento foi conduzido em um pomar experimental pertencente ao Centro Tecnológico da Cooperativa Corol, localizado no município de Rolândia, PR, cujas coordenadas geográficas são $23^{\circ}$ $27^{\prime} \mathrm{S}$ e $51^{\circ} 47^{\prime} \mathrm{W}$, com $600 \mathrm{~m}$ de altitude, precipitação média anual de $1610 \mathrm{~mm}$ e temperatura média anual de $21,2^{\circ} \mathrm{C}$. Foi estudado o comportamento fenológico e as exigências térmicas das videiras 'Isabel' (Vitis labrusca) e 'Rubea' (V. labrusca), enxertadas sobre os portas-enxertos 'IAC 766 Campinas' (Riparia do Traviú $x$ Vitis caribaea), 'IAC 572 Jales' ( $V$. caribaea $\mathrm{x}$ Vitis riparia $\mathrm{x}$ Vitis rupestris 101-14) e '420-A' (Vitis berlandieri x V. riparia).

O delineamento experimental adotado foi o inteiramente casualizado, com 4 repetições, com os tratamentos arranjados no esquema fatorial $2 \times 3$ (2 cultivares copa e 3 cultivares porta-enxerto), sendo cada parcela composta por 5 plantas.

O material vegetal, livre de vírus, foi obtido junto ao Banco de Germoplasma da Embrapa Uva e Vinho, localizada em Bento Gonçalves, RS. O plantio dos portas-enxertos foi realizado em julho de 2002 e a enxertia das copas em julho de 2003. As plantas foram conduzidas no sistema GDC (Geneva Double Curtain), no espaçamento de 2,0 m entre plantas e 3,5 m entre linhas. Em 2004 foi concluída a formação das videiras.

A poda de frutificação foi realizada no dia 31 de agosto de 2005, após o fim do período hibernal, quando se deu início o inchamento das gemas, deixando-se 2 gemas por esporão. Em seguida, foi aplicado o regulador de crescimento cianamida hidrogenada (2,5\%) para a quebra de dormência das gemas, com objetivo de uniformizar a brotação.

Para determinar o tempo decorrido da poda até os diferentes estádios fenológicos, foram etiquetados quatro esporões por parcela, avaliados através de observações visuais. Os estádios determinados seguiram classificação com base em Baggiolini (1952); Pedro Júnior et al. (1989) e Baillod e Baggiolini (1993): 
a) Gema-algodão: quando $50 \%$ das gemas atingirem o segundo estádio de desenvolvimento da videira, ou seja, quando as escamas se romperem e aparecer a plumagem.

b) Brotação: quando $50 \%$ das gemas atingirem o quarto estádio, ou seja, a saída das folhas.

c) Aparecimento da inflorescência: quando $50 \%$ dos ramos apresentarem inflorescência, com os cachos visíveis, embora rudimentares

d) Florescimento: quando $50 \%$ das flores se encontrarem abertas (florescimento propriamente dito com flores visíveis).

e) Início da maturação das bagas: quando $50 \%$ das bagas mudarem para coloração avermelhada e iniciarem o amolecimento.

f) Colheita: momento em que $100 \%$ das bagas se apresentarem macias, de coloração intensa e teor de sólidos sóluveis totais estável.

A partir destes dados, foram construídos diagramas, representando, em escala a duração em dias, de cada uma das fases fenológicas.

Para a caracterização das exigências térmicas das cultivares, foi utilizado o somatório de graus-dia (GD), desde a poda até a colheita, bem como para cada um dos subperíodos, empregando-se dados climáticos da Estação Meteorológica da Cooperativa Corol, segundo as seguintes equações, propostas por Villa Nova et al. (1972):
a) $\mathrm{GD}=\left(\mathrm{T}_{\mathrm{m}}-\mathrm{T}_{\mathrm{b}}\right)+\left(\mathrm{T}_{\mathrm{M}}-\mathrm{T}_{\mathrm{m}}\right) / 2$, para $\mathrm{T}_{\mathrm{m}}>\mathrm{T}_{\mathrm{b}}$;
b) $\mathrm{GD}=\left(\mathrm{T}_{\mathrm{M}}-\mathrm{T}_{\mathrm{b}}\right)^{2} / 2\left(\mathrm{~T}_{\mathrm{M}}-\mathrm{T}_{\mathrm{m}}\right)$, para $\mathrm{T}_{\mathrm{m}}<\mathrm{T}_{\mathrm{b}}$; $\mathrm{e}$
c) $\mathrm{GD}=0$, para $\mathrm{T}_{\mathrm{b}}>\mathrm{T}_{\mathrm{M}}$
onde:
$\mathrm{GD}=$ graus-dia;
$\mathrm{T}_{\mathrm{M}}=$ temperatura máxima diária $\left({ }^{\circ} \mathrm{C}\right)$;
$\mathrm{T}_{\mathrm{m}}=$ temperatura mínima diária $\left({ }^{\circ} \mathrm{C}\right)$;
$\mathrm{T}_{\mathrm{b}}=$ temperatura base $\left(10{ }^{\circ} \mathrm{C}\right)$ (VILLASECA; NOVOA; MUÑOZ, 1986)

\section{Resultados e Discussão}

Na Figura 1 está representada a quantidade de dias transcorridos a partir da poda de frutificação até os diferentes estádios fenológicos da videira 'Isabel' sobre os diferentes porta-enxertos. Observase que, sobre o '420-A' o ciclo total desta videira foi mais longo (167 dias) comparado aos porta-enxertos 'AC 766 Campinas' e 'IAC 572 Jales' (148 e 142 dias, respectivamente), sendo que a diferença mais evidente entre estas combinações se deu principalmente do início da maturação à colheita $(68$, 49 e 41 dias quando sobre '420-A', 'IAC 766 Campinas' e 'IAC 572 Jales', respectivamente).

Para a cultivar Rubea, os porta-enxertos não exerceram influência sobre o tempo transcorrido da poda de frutificação até os diferentes estádios fenológicos (Figura 2), sendo a duração do ciclo semelhante para todas as combinações $(134,134 \mathrm{e}$ 132 dias, sobre 'IAC 766 Campinas', 'IAC 572 Jales' e '420-A', respectivamente). O ciclo da combinação 'Rubea'/'420-A' foi diferente do esperado, pois este porta-enxerto é conhecido por prolongar o ciclo das cultivares copa nele enxertadas. Entretanto, devese considerar que as videiras desta combinação não apresentavam o mesmo vigor das demais combinações, uma vez que o desenvolvimento das plantas sobre este porta enxerto é mais lento. Desta forma, é provável que neste período a diferença de vigor entre as videiras tenha influenciado na duração do ciclo desta combinação.

Ressalta-se, também, que a variação na duração do ciclo de algumas combinações copa/porta-enxerto, pode ser explicada pela diferença de afinidade entre as duas partes (KUHN et al., 1996). Alvarenga et al. (2002a) estudaram a influência dos cultivares porta-enxertos IAC 766 Campinas, IAC 572 Jales e 420-A na duração do ciclo da 'Niagara Rosada' no município de Caldas, MG. Verificaram que o 'IAC 572 Jales' proporcionou ciclo mais longo e o ' $420-\mathrm{A}$ ' mais curto. Em outro trabalho, Alvarenga et al. (2002b) verificaram que no Sul de Minas Gerais os mesmos porta-enxertos não influenciaram na duração do ciclo das cultivares Folha de Figo e Jacquez. 
Com relação à duração do ciclo da 'Isabel' e da 'Rubea', pode-se considerar que no Norte do Paraná estas videiras apresentam ciclo médio mais curto, em relação a outras regiões de clima mais ameno. Regina et al. (2003) relatam que, no Sul de Minas Gerais estas cultivares apresentam ciclos de 177 e 164 dias, respectivamente. Segundo Camargo (2006), na Serra Gaúcha, RS, o ciclo da 'Isabel' é de 164 dias, enquanto Maia, Camargo e Nachtigal (2002) relatam que, no município de Campina Verde, MG, a 'Isabel' enxertada sobre os porta-enxertos 'IAC 766 Campinas' e 'IAC 572 Jales' no sistema GDC apresenta ciclo de 141 dias.

Segundo Pedro Júnior e Sentelhas (2003), a duração do ciclo das videiras pode variar entre regiões devido às diferentes condições edafoclimáticas em que se localizam as mesmas, pois em locais com temperatura elevadas o crescimento vegetativo tende a ser superior e o ciclo mais curto em relação a regiões de clima mais ameno.

Em regiões de clima tropical semi-árido, como no Vale do São Francisco, BA, Lima et al. (2004) verificaram que a cultivar Isabel é colhida aos 94 dias após o florescimento, enquanto Roberto et al. (2004) observaram que, para a mesma cultivar em Maringá, PR, a colheita é realizada aos 99 dias após o florescimento, sendo que ambos os ciclos são semelhantes ao observado neste trabalho, onde a colheita foi realizada, em média, 100 dias após o florescimento ('IAC 766 Campinas' e 'IAC 572 Jales').

A relação entre a duração do ciclo e a temperatura pode ser explicada por Mullins, Bouquet e Williams (1992), que descrevem que o desenvolvimento vegetativo e a duração do ciclo das videiras estão relacionados à produção e ao acúmulo de carboidratos das mesmas, por meio do processo de fotossíntese, sendo que as condições climáticas possuem influência direta sobre esse processo. Em temperatura igual ou abaixo de $10^{\circ} \mathrm{C}$, a taxa fotossintética das videiras é praticamente nula. Em regiões de clima ameno, que apresentam temperaturas médias entre 25 e $35^{\circ} \mathrm{C}$, a videira atinge o seu ápice em relação à produção e acúmulo de carboidratos, e com temperaturas superiores a $40{ }^{\circ} \mathrm{C}$ a sua taxa fotossintética começa a cair.

Porém, segundo Pommer, Terra e Pires (2003), no Brasil é possível se encontrar videiras em plena produção de carboidratos sob temperaturas de 40 ${ }^{\circ} \mathrm{C}$. Portanto, pode-se considerar que a relação temperatura-fotossíntese seja a razão para a menor duração do ciclo e ao elevado crescimento vegetativo das videiras em regiões de clima com temperaturas médias mais elevadas.

Para as condições de clima do Norte do Paraná, a quebra de dormência das videiras é feita por meio da aplicação da cianamida hidrogenada nas gemas logo após a poda, com o objetivo de se obter brotação uniforme das mesmas, tendo em vista que esta região não apresenta horas de frio $\left(\mathrm{d}^{\prime} 7,2^{\circ} \mathrm{C}\right)$ suficiente e as temperaturas tendem a oscilar, o que dificulta a quebra natural da dormência e podendo impedir ou levar à brotação desuniforme das gemas, e consequentemente a uma maturação irregular das uvas. Portanto, a data da poda e a quebra da dormência passa a ser referência para o início do ciclo fenológico, o que pode variar de ano para ano.

A demanda térmica da videira 'Isabel', quando enxertada sobre 'IAC 766 Campinas' e 'IAC 572 Jales', foi de 1.260,9 GD, e quando sobre o '420-A' foi maior, de 1.541,6 GD (Tabela 1). Para a videira 'Rubea', a demanda térmica foi menor em relação à 'Isabel', em todas as combinações copa/portaenxerto (Tabela 2), sendo que quando enxertada sobre '420-A' foi de 999,5 GD e sobre os demais porta-enxetos foi de 1.003,8 GD.

A diferença na demanda térmica entre as combinações copa/porta-enxerto está relacionada à duração do ciclo da videira, pois quanto maior a necessidade térmica, mais longo o ciclo tende a ser. Mandelli (1984) verificou que a demanda térmica da videira 'Isabel' na Serra Gaúcha é de 1.393 GD, enquanto Roberto et al. (2002) constataram que em Maringá, PR, a sua demanda quando em pé franco é 
de 1.238,2 GD, resultado semelhante aos obtidos neste trabalho. Deve-se, porém, levar em consideração que o conceito original de GD está relacionado somente à temperatura e desenvolvimento da cultura, não sendo considerado o efeito de outros fatores ambientais sobre o desenvolvimento vegetal. Por esta razão, a demanda térmica das videiras pode variar entre regiões, devido às diferentes condições edafo-climáticas (PEZZOPANE et al., 2005).
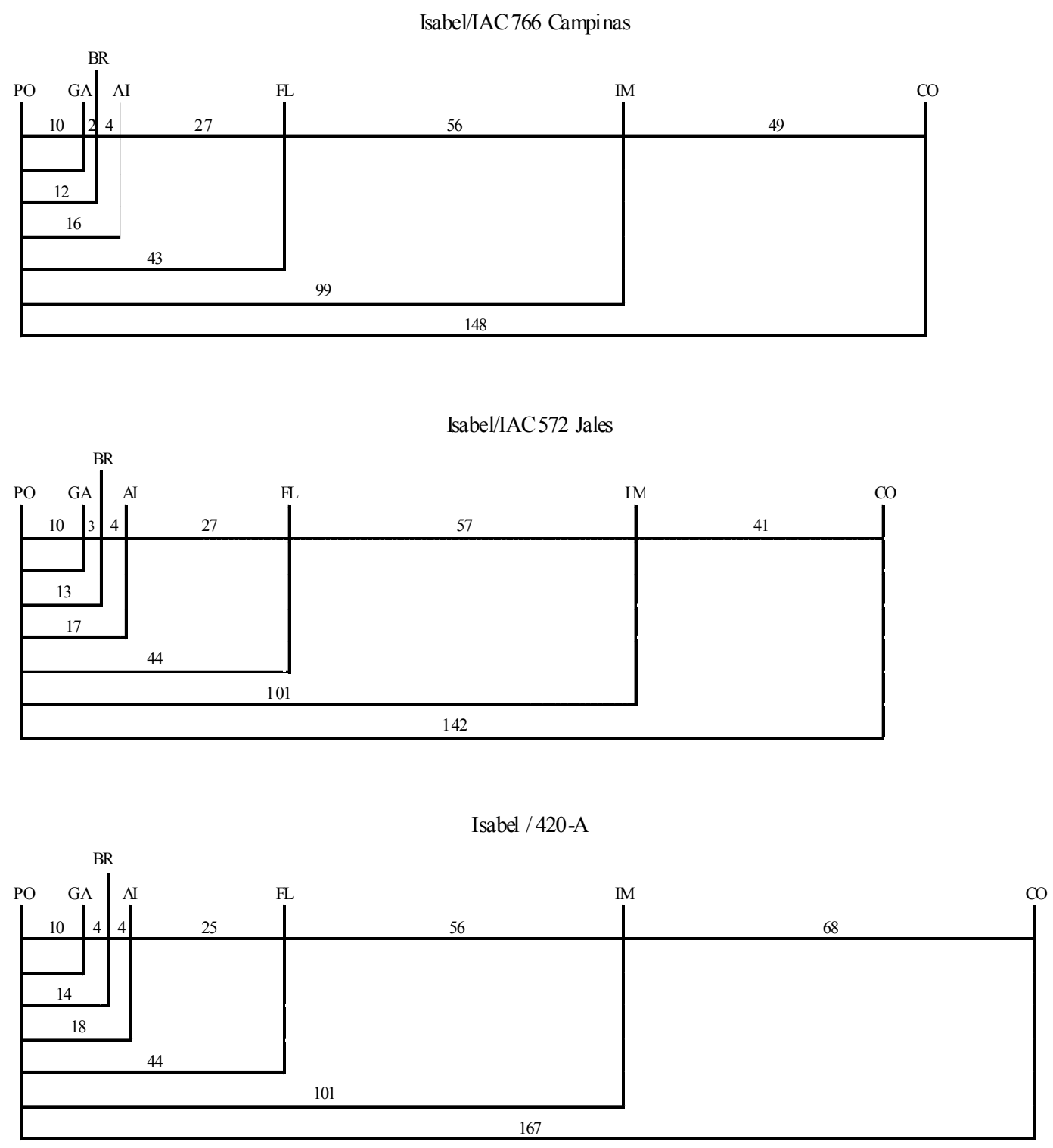

Figura 1. Dias transcorridos da poda até os diferentes estádios fenológicos da uva 'Isabel' enxertada sobre os portaenxertos 'IAC 766 Campinas', 'IAC 572 Jales' e '420 A'. Poda (PO); gema-Algodão (GA); brotação (BR); aparecimento da inflorescência (AI); florescimento (FL); início da maturação das bagas (IM); colheita (CO). Londrina, PR. Safra 2005/2006. 
Rubea/766 Campinas

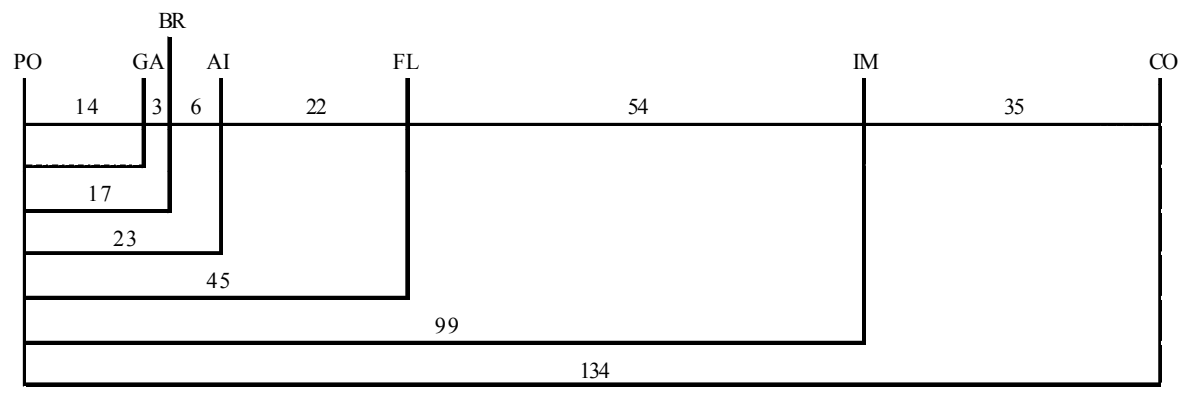

Rubea/IAC 572 Jales

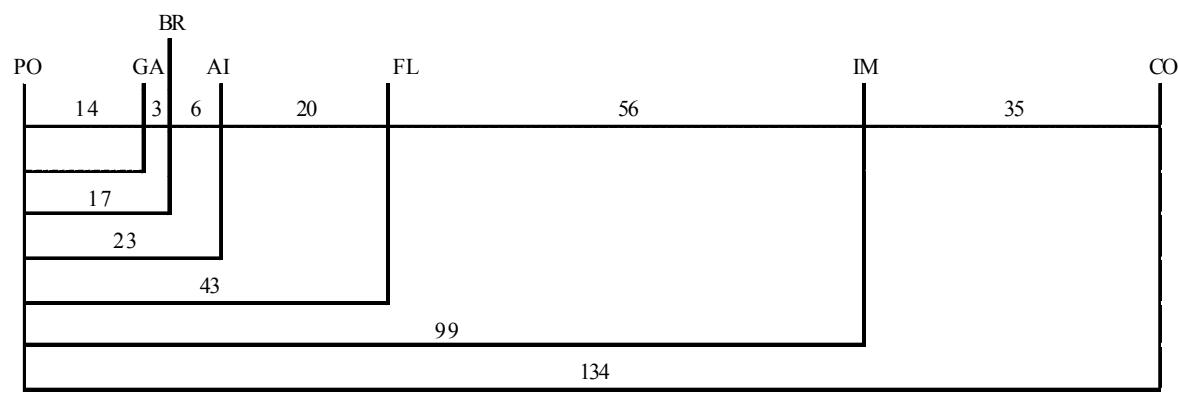

Rubea/420-A

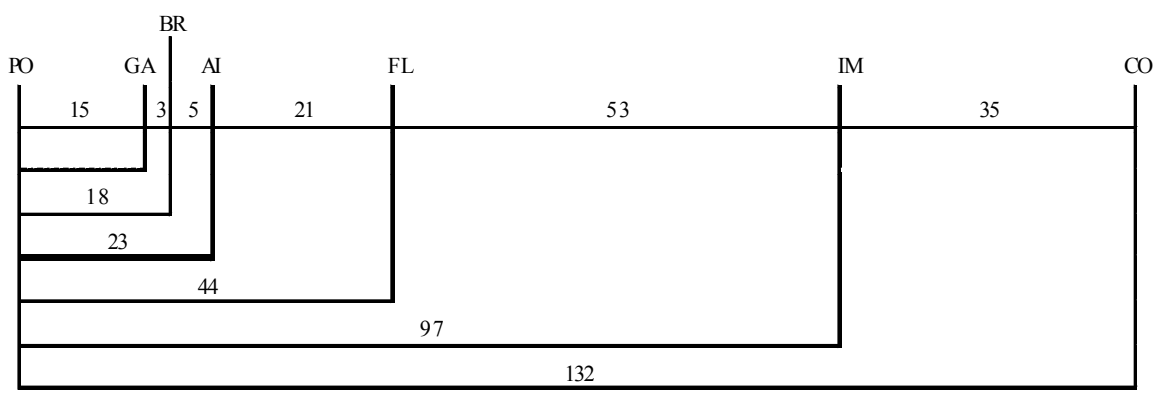

Figura 2. Dias transcorridos da poda até os diferentes estádios fenológicos da uva 'Rubea' enxertada sobre os portaenxertos 'IAC 766 Campinas', 'IAC 572 Jales’ e ‘420-A’. Poda (PO); gema-Algodão (GA); brotação (BR); aparecimento da inflorescência (AI); florescimento (FL); início da maturação das bagas (IM); colheita (CO). Londrina, PR. Safra $2005 / 2006$.

Na Região Norte do Paraná, as condições climáticas oscilam muito de ano para ano, podendo variar o ciclo, portanto deve-se estar sempre atento às previsões climáticas de cada ano para realizar a poda no momento adequado e obter a colheita no período em que a demanda por uvas para processamento é maior, ou de acordo com a programação feita junto às indústrias de sucos de uva.

Os resultados apresentados neste trabalho, embora propiciem indicações sobre a fenologia, devem ser considerados preliminares, devendo ser confirmados após vários ciclos produtivos. 
Tabela 1. Soma térmica, em graus-dia (GD), calculada com a temperatura-base de $10^{\circ} \mathrm{C}$ para a uva 'Isabel', enxertada sobre os porta enxertos 'IAC 766 Campinas', 'IAC 572 Jales’ e ‘420-‘A. Londrina, PR. Safra 2005/ 2006.

\begin{tabular}{cccc}
\hline Subperíodos & 'Isabel'/'IAC 766' & 'Isabel'/'IAC 572' & 'Isabel'/'420-A' \\
\hline PO-GA & 72,2 & 72,2 & 72,2 \\
GA-BR & 20,6 & 24,5 & 25,8 \\
BR-AI & 16,5 & 21,0 & 27,7 \\
AI-FL & 210,3 & 191,4 & 193,9 \\
FLO-IM & 497,5 & 508,0 & 497,5 \\
IM-CO & 443,7 & 443,7 & 724,5 \\
\hline PO-CO & $1.260,9$ & $1.260,9$ & $1.541,6$ \\
\hline
\end{tabular}

PO-GA: poda - gema algodão; GA-BR: gema algodão - brotação; BR-AI: brotação - aparecimento da inflorescência; AIFL: aparecimento da inflorescência - florescimento; FL-IM: florescimento - início da maturação; IM-CO: início da maturação - colheita; PO-CO: poda - colheita.

Tabela 2. Soma térmica, em graus-dia (GD), calculada com temperaturas-base de $10^{\circ} \mathrm{C}$, para a uva 'Rubea', enxertada sobre os porta enxertos 'IAC 766 Campinas', 'IAC 572-Jales' e ‘420-A'. Londrina. Safra 2005/2006.

\begin{tabular}{cccc}
\hline Subperíodos & 'Rubea'/'IAC 766' & 'Rubea'/'IAC 572' & 'Rubea'/ '420-A' \\
\hline PO-GA & 98,0 & 98,0 & 98,0 \\
GA-BR & 19,7 & 19,7 & 20,1 \\
BR-AI & 44,6 & 44,6 & 35,4 \\
AI-FL & 180,4 & 157,2 & 169,2 \\
FL-IM & 474,3 & 497,5 & 490,1 \\
IM-CO & 186,7 & 186,7 & 186,7 \\
\hline PO-CO & $1.003,8$ & $1.003,8$ & 999,5 \\
\hline
\end{tabular}

PO-GA: poda - gema algodão; GA-BR: gema algodão - brotação; BR-AI: brotação - aparecimento da inflorescência; AIFL: aparecimento da inflorescência - florescimento; FL-IM: florescimento - início da maturação; IM-CO: início da maturação - colheita; PO-CO: poda - colheita.

\section{Conclusões}

Para as condições do Norte do Paraná, a videira 'Isabel' é mais tardia, com a duração do ciclo e a demanda térmica influenciada pelo porta-enxerto, sendo superior quando enxertada sobre o ' $420-\mathrm{A}$ ' (167 dias e 1.541,6 GD), em relação ao 'IAC 766 Campinas' e o 'IAC 572 Jales' (148 e 142 dias, com 1.260,9 GD e 1.260,9 GD, respectivamente). O ciclo e a demanda térmica da 'Rubea' não é influenciada pelos porta-enxertos (132 a 134 dias e 999,5 GD a $1.003,8 \mathrm{GD})$, demonstram maior precocidade em relação a 'Isabel'.

\section{Agradecimentos}

Agradeço ao CNPq pelo apoio financeiro e à Cooperativa Corol pela cessão da área para realização do experimento. 


\section{Referências}

ALVARENGA, A. A.; REGINA, M. A.; FRÁGUAS, J. C.; CHALFUN N. N. J.; SILVA, A. L. Influência do porta-enxerto sobre o crescimento e produção da cultivar de videira Niágara Rosada (Vitis labrusca L. x Vitis vinifera L.), em condições de solo ácido. Ciência e Agrotecnologia, Lavras, v. 26, p. 1459-1464, 2002a. Edição especial.

ALVARENGA, A. A.; REGINA, M. A.; FRÁGUAS, J. C.; SILVA, A. L.; SOUZA, C. M.; CANÇADO, G. M. A.; FREITAS, F. F. Indicação de porta-enxertos de videiras para o sul de Minas Gerais. In: REGINA, M. A.; ANTUNES, L. E. C.; DUARTE FILHO, J.; FADINI, M. A. M.; CANÇADO, G. M. A.; ALVARENGA, A. A.; AMORIM, D. A.; SOUZA, C. M.; PÁDUA, J. G. Viticultura e enologia: atualizando conceitos. Andradas: EPAMIG-CECD, 2002 b. p. 243-256.

BAGGIOLINI, M. Les stades repères dans le developpement anual de la vigne. Revue Romande d'Agriculture, de Viticulture et d'Arboriculture, Lausanne, v. 8, p. 4-6, 1952.

BAILLOD, M.; BAGGIOLINI, M. Les stades repères de la vigne. Revue Suisse Viticulture Arboriculture et Horticulture, Nyon, v. 25, n. 1, p. 7-9, 1993.

CAMARGO, U. A. Espécies e cultivares. In: EMPRESA BRASILEIRA DE PESQUISA AGROPECUÁRIA EMBRAPA/CNPUV. Uva para processamento $e$ produção. Brasília: Embrapa Informação Tecnológica, 2003. p. 34-44.

- Suco de uva: matéria-prima para produtos de qualidade e competitividade. In: CONGRESSO LATINOAMERICANODE VITICULTURA E ENOLOGIA, 10., 2005, Bento Gonçalves. Anais... Bento Gonçalves: Embrapa Uva e vinho, 2005. p. 195.

- Uvas americanas e híbridas para processamento em clima temperado. Disponível em: $<$ www.cnpuv.embrapa.br/publica/sprod/.htm>. Acesso em: 24 maio 2006.

CORRÊA, S. C.; BOLIANI, A. C. O cultivo de uva de mesa no Brasil e no mundo e sua importância econômica. In: SIMPÓSIO BRASILEIRO DE UVAS DE MESA, 1., 2000, Ilha Solteira-SP. Anais... Ilha Solteira: Sociedade Brasileira de Fruticultura, 2000. p. 1-19.

EMPRESA BRASILEIRA DE PESQUISA AGROPECUÁRIA - EMBRAPA Uva e Vinho. Brasil vitivinicola: regiões produtoras. Disponível em: $<$ http:// www.cnpuv.embrapa.br/publica/palestras $>$. Acesso em: 25 maio 2005.
. Uvas americanas e híbridas para processamento

em clima temperado. Disponível em: $<$ www.cnpuv.embrapa.br/publica/sprod/.htm $>$. Acesso em: 24 maio 2006.

KUHN, G. B.; LOVATEL, J.L.; PREZOTTO, O. P.; RIVALDO, O. F.; MANDELLI, F.; SÔNEGO, O. R. O cultivo da videira: informações básicas. 2.ed. Bento Gonçalves: EmbrapaCNPUV, 1996. (Circular Técnica, 10).

LIMA, M. A. C.; LEÃO, P. C. S.; SILVA, A. L.; AZEVEDO, S. S. N.; SANTOS, P. S. Maturação de uvas para vinho no Vale do São Francisco. In: CONGRESSO BRASILEIRO DE FRUTICULTURA, 18., 2004, Florianópolis. Anais... Florianópolis: EPAGRI, 2004. CDROM.

MAIA, J. D. G.; CAMARGO, U. A.; NACHTIGAL, J. C. Avaliação da cv. Isabel em três sistemas de condução e em dois porta-enxertos para a produção de suco em região tropical. In: CONGRESSO BRASILEIRO DE FRUTICULTURA, 17., 2002, Belém. Anais... Belém: SBF, 2002. CDROM.

MANDELLI, F. Comportamento fenológico das principais cultivares de Vitis vinifera L. para a região de Bento Gonçalves, RS. 1984. Dissertação (Mestrado em Agrometeorologia) - Escola Superior de Agricultura Luiz de Queiroz, Universidade de São Paulo, Piracicaba.

MELLO, L. M. R. Panorama. In: Anuário Brasileiro da Uva e do Vinho. Santa Cruz do Sul: Gazeta, 2006. p. 17-18

. Produção e comercialização de uvas e vinhos: panorama 2003. Disponível em: <http:// www.vinhosnet.com.br/lv1.asp>. Acesso em: 28 maio 2005.

MULLINS, M. G.; BOUQUET, A.; WILLIAMS, L. E. Biology of the grapevine. Cambridge: University Press, 1992.

NACHTIGAL, J. C.; CAMARGO, U. A. Recomendações para o manejo da planta e dos cachos das cultivares de uvas de mesa sem semente - BRS Morena, BRS Clara e BRS Linda. Bento Gonçalves: Embrapa Uva e Vinho, 2004. p. 15 (Circular Técnica, 51).

PEDRO JÚNIOR, M. J.; RIBEIRO, I. J.A.; POMMER, C. V.; MARTINS, F. P. Caracterização de estágios fenológicos da videira 'Niagara Rosada'. In: CONGRESSO BRASILEIRO DE FRUTICULTURA, 10., 1989, Fortaleza. Anais... Fortaleza: SBF, 1989. v.1, p.453-456.

PEDRO JÚNIOR, M. J.; SENTELHAS, P. C. Clima e produção. In: POMMER, C. V. Uva: tecnologia de produção, pós-colheita, mercado. Porto Alegre: Cinco Continentes, 2003. p. 63-107. 
PEZZOPANE, J. R. M.; PEDRO JÚNIOR, M. J.; CAMARGO, M. B. P.; FAZUOLI, L. C. Temperatura-base e graus-dia com correção pela disponibilidade hídrica para o cafeeiro Mundo Novo no período de florescimentocolheita. In: CONGRESSO BRASILEIRO DE AGROMETEOROLOGIA, 14., 2005, Campinas. Anais... Campinas: SBA, 2005. v.1, p. 9-10.

POMMER, C. V.; TERRA, M. M.; PIRES, E. J. P. Cultivares, melhoramento e fisiologia. In: POMMER, C. V. Uva: tecnologia de produção, pós-colheita, mercado. Porto Alegre: Cinco Continentes, 2003. p. 109-152.

REGINA, M. A.; PEREIRA, G. E.; LIMA, L. C. O.; RODRIGUES, D. J. Caracterização agronômica de cinco variedades de videira destinadas à elaboração de sucos de uvas na região de Caldas-MG. In: CONGRESSO BRASILEIRODE VITICULTURA EENOLOGIA, 10., 2003, Bento Gonçalves. Anais... Bento Gonçalves: Embrapa Uva e Vinho, 2003.p. 197.

RIZZON, L. A.; MANFROI, V.; MENEGUZZO, J. Elaboração de suco na propriedade vitícola. Bento Gonçalves: Embrapa Uva e Vinho, 1998.
ROBERTO, S. R.; KANAI, H. T.; YANO, M. Y.; SASANO, E. M.; GENTA, W. Efeito da poda de frutificação sobre a fertilidade de gemas da videira 'Niagara Rosada' produzida fora de época no Paraná. Semina: Ciências Agrárias, Londrina, v. 23, n. 2, p. 148, 2002.

ROBERTO, S. R.; SATO, A. J.; BRENNER, E. A.; SANTOS, C. E.; GENTA, W. Fenologia e soma térmica (graus-dia) para videira 'Isabel' (Vitis labrusca) cultivada no Norte do Paraná. Semina: Ciêncas Agrárias, Londrina, v. 25, n. 4, p. 273-280, 2004.

SENTELHAS, P. C. Aspectos climáticos para viticultura tropical. Informe Agropecuário, Belo Horizonte, v. 19, n. 194, p. 9-14, 1998.

VILLA NOVA, N. A.; PEDRO JÚNIOR, M. J.; PEREIRA, A. R.; OMETTO, J. C. Estimativa de graus-dia acumulados acima de qualquer temperatura base em função das temperaturas máxima e mínima. São Paulo: USP - Instituto de Geografia, 1972. (Caderno Ciência da Terra, 30).

VILLASECA, S.C.;NOVOA, R. S. A;MUÑOZ, I.H.Fenologia y sumas de temperaturas en 24 variedades de vid. Agricultura Técnica, Santiago, v. 46, n. 1, p. 63-67, 1986. 